\title{
Analisis Bioinformatika Berbasis WEB untuk Eksplorasi Enzim Kitosanase Berdasarkan Kemiripan Sekuens
}

\author{
Vanny Narita ${ }^{1,3, *}$, Arif Lelono Arum ${ }^{1}$, Siti Isnaeni $\mathbf{M}^{1}$, Nuri Y. Fawzya ${ }^{2}$ \\ ${ }^{1}$ Program Studi Biologi (Bioteknologi), Fakultas Sains dan Teknologi, \\ Universitas Al Azhar Indonesia, Jl. Sisingamangaraja, Jakarta 12110 \\ ${ }^{2}$ Balai Besar Riset Pengolahan Produk dan Bioteknologi Kelautan dan Perikanan, \\ Kementerian Kelautan dan Perikanan, Jl. KS Tubun Raya Petamburan 6, Jakarta Pusat, 10260 \\ ${ }^{3}$ Pusat Teknologi Farmasi dan Medika, Badan Pengkajian dan Penerapan Teknologi, \\ Jl. MH Thamrin No. 8, Gedung II BPPT, Lantai 15, Jakarta Pusat, 13340 \\ "Penulis untuk korespondensi: vanny_narita@uai.ac.id
}

\begin{abstract}
Abstrak - Eksplorasi enzim secara tradisional dengan kultivasi mikroba sekarang ini tidak lagi efisien, karena menghabiskan waktu dan biaya. Bioinformatik berbasis web hadir untuk melakukan serangkaian analisis sekuen, baik itu DNA maupun protein, yang dapat digunakan sebagai penelitian pendahuluan, sehingga ekplorasi enzim menjadi lebih tepat sasaran. Penelitian ini telah melakukan analisis potongan sekuen 16S ribosomal RNA yang didapat dari 6 bakteri yang berasosiasi dengan udang. Analisis yang dilakukan adalah untuk mencari tahu tersedianya sekuen tersebut telah ada di Gene Bank atau merupakan strain baru khas Indonesia yang belum terpublikasi. Dengan menggunakan database $16 \mathrm{~S}$ Microbial dan Reference Genomic Sequence, serta fasilitas BLAST nucleotide dan CLUSTALW2 didapatkan 5 nama bakteri yaitu Micromonospora sp. L5, Aeromonas veronii B565, Staphylococcus epidermidis ATCC 12228, Burkholderia sp. JV3, dan Acinetobacter baumannii AB307-0294. Kelima mikroba ini memiliki tidak mempunyai gen kitosanase tetapi penyandi kitinase. Ketidakhadiran gen kitosanase dalam genome mikroba menjadikan mikroba unik untuk diketahui sekuens gen kitosanasenya, yang juga berpeluang untuk dipublikasikan.
\end{abstract}

Abstract - Enzymes exploration which is traditionally conducted by microbial cultivation, is no longer efficient, for spending the time and cost. Web based bioinformatics presents to do a series of sequence analysis, for query both DNA and protein, which can be used as preliminary test in order to direct the research effectively. We have conducted an analysis of $16 \mathrm{~S}$ ribosomal RNA sequences from 6 bacteria in association with shrimp. The goal is finding out the recording in Gene Banks, which if they have not recorded means they are Indonesian strain. Using the 16S Microbial and Reference Genomic Sequence databases, as well as BLAST nucleotide and CLUSTALW2, we obtained 5 names of bacteria, i.e., Micromonospora sp. L5, Aeromonas veronii B565, Staphylococcus epidermidis ATCC 12228, Burkholderia sp. JV3, and Acinetobacter baumannii AB307-0294. These microbes do not have the chitosanase gene but have chitinase gene. The absence of chitosanase gene is unique its sequence that also gives opportunity for publication.

Keywords - Bioinformatics, Enzyme, Kitosanase, Sequence

\section{PENDAHULUAN}

$\mathrm{E}$ ksplorasi enzim merupakan hal yang penting untuk menunjang perkembangan teknologi bio yang lebih ramah lingkungan. Pencarian mikroba secara tradisional dengan kultivasi sekarang ini menjadi lebih tidak efisien karena menghabiskan biaya dan tenaga. Bioinformatik hadir sebagai alternatif pencarian sekuen enzim baru menggunakan analisis filogeni (kekerabatan) untuk mencari spesies terdekat berdasarkan data genome yang di Gene Bank. Situs yang menyediakan fitur ini adalah National Center for Biotechnology Information yang secara online [1]. 
Metode bioinformatik berbasis web digunakan untuk mencari anotasi (penamaan), pemetaan genome, dan analisis sekuen lanjut lainnya yang dijalankan secara online melalui program yang tersedia secara gratis di web. Keunggulan metode tersebut adalah hemat dan dapat menjadi penelitian pendahuluan sebelum percobaan secara nyata dilakukan [2-5].

Penelitian bioinformatik berbasis web ini bertujuan untuk melakukan eksplorasi enzim kitosanase dengan program berbasis web, dengan menggunakan potongan sekuen $16 \mathrm{~S}$ ribosomal RNA (16S rRNA). Analisis yang dilakukan adalah untuk mencari tahu apakah sekuen tersebut telah ada di Gene Bank atau merupakan strain baru khas Indonesia yang belum terpublikasi. Diharapkan hasil penelitian ini dapat membantu memberikan anotasi (penamaan) untuk strain baru yang memudahkan analisis sekuen DNA dan protein secara lebih lanjut.

Kitosanase adalah sekelompok enzim yang mencerna kitosan tetapi bukan kitin. Menurut Enzyme Commission definisi kitosanase sendiri adalah enzim yang mampu melakukan endohidrolisis ikatan beta-1,4 antarresidu Dglukosamin menjadi kitosan terasetilasi sebagian [6]. Enzim ini sangat penting untuk menjaga keseimbangan antara karbon dan nitrogen yang terjebak sebagai kitin terlarut dalam biomassa [7]. Di bidang kesehatan, kitosanase dari jamur patogen telah terbukti menjadi faktor virulensi putatif, dan dapat memainkan peran penting dalam menginfeksi inang [8].

\section{TINJAUAN PUSTAKA}

Bioinformatik adalah gabungan disiplin ilmu biologi, ilmu komputer, informatika, matematika, dan disiplin lain yang terkait yang menjadi disiplin tersendiri. Tujuan utamanya adalah mampu memberikan pandangan baru dalam mencapai prespektif global yang menunjang perkembangan bioteknologi di masa depan [4,9]. Analisis dalam bioinformatika difokuskan pada tiga jenis dataset: urutan genom, struktur makromolekul dan percobaan genomik fungsional. Tetapi analisis bioinformatika juga diterapkan pada berbagai data lain, seperti pohon taksonomi, data tentang hubungan jalur metabolik, teks artikel ilmiah dan statistik. Berbagai macam teknik yang digunakan termasuk pencocokan sekuen, struktur protein 3D, konstruksi pohon filogenetik, prediksi dan klasifikasi struktur protein, prediksi struktur RNA, prediksi fungsi protein, dan ekspresi kluster data $[10,4]$.

Contoh analisis kitosanase berbasis filogeni yang telah dikembangkan adalah menggunakan gen $16 \mathrm{~S}$ rRNA dari data metagenomik yang menunjukkan bahwa salinitas merupakan penggerak utama untuk distribusi bakteri chitinolytic dan total komunitas bakteri dalam sistem perairan [11]. Selain itu, gen chiA dari Aeromonas caviae yang mengkode kitosanase ekstraselular dengan panjang 865 asam amino telah diketahui menunjukkan tingkat tinggi kesamaan mirip dengan kitosanase A Serratia marcescen secara bioinformatik [12].

\section{METODE PENELITIAN}

Sampel merupakan sekuen 16S ribosomal RNA yang diamplifikasi dengan primer maju dan mundur, sehingga mengghasilkan dua potongan sekuen masing-masing 500 bp. Pada umumnya panjang sekuen 16S rRNA yang lengkap adalah $1.500 \mathrm{bp}$, sehingga dalam penelitian ini potongan tengah sekuen tidak digunakan. Sekuen berasal dari bakteri penghasil kitosanase yang berasosiasi dengan udang.

$>$ T5al $\mathrm{F}$

CGCGT'̄AGCTTCGGGGTCTCGAGCGGCGACGGGTGAGTAACACGTGA GCAACCTGCCCCAGGCTTTGGGATAACCCCGGGAAACCGGGGCTAAT ACCGAATATGACCTTGCACCGCATGGTGTTTGGTGGAAAGTTTTTCG GCTTGGGATGGGCTCGCGGCCTATCAGCTTGTTGGTGGGGTGATGGC CTACCAAGGCGACGACGGGTAGCCGGCCTGAGAGGGCGACCGGCCAC ACTGGGACTGAGACACGGCCCAGACTCCTACGGGAGGCAGCAGTGGG GAATATTGCACAATGGGCGGAAGCCTGATGCAGCGACGCCGCGTGAG GGATGACGGCCTTCGGGTTGTAAACCTCTTTCAGCAGGGACGAAGCG TAAGTGACGGTACCTGCAGAAGAAGCGCCGGCCAACTACGTGCCAGC AGCCGCGGTAAGACGTAGGGCGCGAGCGTTGTCCGGATTTATTGGGC GTAAAGAGCTCGTAGGCGGCTTGTCGCGTCGACCGTGAAAACCTGGG GCTCAACCCCAGGCCTGCGGTCGATACGGGCAGGCTAGAGTTCGGTA GGGGAGACTGGAATTCCTGGTGTAGCGGTGAAATGCGCAGATATCAG GAGGAACACCGGTGGCGAAGGCGGGTCTCTGGGCCGATACTGACGCT GAGGAGCGAAAGCGTGGGGAGCGAACAGGATTAGATACCCTGGTAGT CCACGCTGTAAACGTTGGGCGCTAGGTGTGGGGGG

$>\mathrm{T} 5 \mathrm{a} 1 \mathrm{R}$

ССTCTC CGGTTCCCTGTGCCGCAGCTAACGCATTAAGCGCCCCGCCT GGGGAGTACGGCCGCAAGGCTAAAACTCAAAGGAATTGACGGGGGCC CGCACAAGCGGCGGAGCATGCGGATTAATTCGATGCAACGCGAAGAA CCTTACCTGGGTTTGACATGGCCGCAAAACTGTCAGAGATGGCAGGT CCTTCGGGGGCGGTCACAGGTGGTGCATGGCTGTCGTCAGCTCGTGT CGTGAGATGTTGGGTTAAGTCCCGCAACGAGCGCAACCCTCGTTCGA TGTTGCCAGCGCGTTATGGCGGGGACTCATCGAAGACTGCCGGGGTC AACTCGGAGGAAGGTGGGGATGACGTCAAGTCATCATGCCCCTTATG TCCAGGGCTTCACGCATGCTACAATGGCCGGTACAATGGGCTGCGAT ACCGTGAGGTGGAGCGAATCCCAAAAAGCCGGTCTCAGTTCGGATCG GGGTCTGCAACTCGACCCCGTGAAGTCGGAGTCGCTAGTAATCGCAG ATCAGCGCTC

$>\mathrm{KPU} 21.24 \mathrm{~F}$

GGCAGMSGGAĀATGCTTGCTCTTTTGCCGGCGAGCGGCGGACGGGTG AGTAATGCCTGGGAAATTGCCCAGTCGAGGGGGATAACAGTTGGAAA CGACTGCTAATACCGCATACGCCCTACGGGGGAAAGCAGGGGACCTT CGGGCCTTGCGCGATTGGATATGCCCAGGTGGGATTAGCTTGTTGGT GAGGTAATGGCTCACCAAGGCGACGATCCCTAGCTGGTCTGAGAGGA 
TGATCAGCCACACTGGAACTGAGACACGGTCCAGACTCCTACGGGAG GCAGCAGTGGGGAATATTGCACAATGGGGGAAACCCTGATGCAGCCA TGCCGCGTGTGTGAAGAAGGCCTTCGGGTTGTAAAGCACTTTCAGCG AGGAGGAAAGGTTGATACCTAATACGTATCAGCTGTGACGTTACTCG CAGAAGAAGCACCGGCTAACTCCGTGCCAGCAGCCGCGGTAATACRG AGGGTGCRAGCGTTAATCGGAATTACTGGGCGTAAAGC

$>$ KPU21.24R

GCACGCAGGCGGGTTGGATAAGTTAGATGTGAAAGCCCCGGGCTCAAC CTGGGAATTGCATTTAAAACTGTCCAGCTAGAGTCTTGTAGAGGGGG GTAGAATTCCAGGTGTAGCGGTGAAATGCGTAGAGATCTGGAGGAAT ACCGGTGGCGAAGGCGGCCCCCTGGACAAAGACTGACGCTCAGGTGC GAAAGCGTGGGGAGCAAACAGGATTAGATACCCTGGTAGTCCACGCC GTAAACGATGTCGATTTGGAGGCTGTGTCCTTGAGACGTGGCTTCCG GAGCTAACGCGTTAAATCGACCGCCTGGGGAGTACGGCCGCAAGGTT AAAACTCAAATGAATTGACGGGGGCCCGCACAAGCGGTGGAGCATGT GGTTTAATTGATGCAACGCGAAGAACCTTACCTGGCCTTGACATGTC TGGAATCCTGTAGAGATACGGGAGTGCCTTCGGGAATCAGAACACAG GTGCTGCATGGCTGTCGTCAGCTCGTGTCGTGAGATGTTGGGTTAAG TCCCGCAACGAGCGCAACCCCTGTCCTTTGTTGCCAGCACGTAATGG TGGGAACTCAAGGGAGACTGCCGGTGATAAACCGGAGGAAGGTGGGG ATGACGTCAAGTCATCATGGCCCTTACGGCCAGGGCTACACACGTGC TACAATGGCGCGTACAGAGGGCTGCAAGCTAGCGATAGTGAGCGAAT CCCAAAAAGCGCGTCGTAGTCCGGATCGGAGTCTGCAACTCGACTCC GTGAAGTCGGAATCGCTAGATCGCAAATCAGAATGGTGCCC

$>$ KLU11.16 F

NNNNNNNNNNGĒNNNNNGCTTGCTACTTTTGCCGGCGAGCGGCGGACG GGTGAGTAATGCCTGGGAAATTGCCCAGTCGAGGGGGATAACAGTTG GAAACGACTGCTAATACCGCATACGCCCTACGGGGGAAAGCAGGGGA CCTTCGGGCCTTGCGCGATTGGATATGCCCAGGTGGGATTAGCTTGT TGGTGAGGTAATGGCTCACCAAGGCGACGATCCCTAGCTGGTCTGAG AGGATGATCAGCCACACTGGAACTGAGACACGGTCCAGACTCCTACG GGAGGCAGCAGTGGGGAATATTGCACAATGGGGGAAACCCTGATGCA GCCATGCCGCGTGTGTGAAGAAGGCCTTCGGGTTGTAAAGCACTTTC AGCGAGGAGGAAAGGTTGATACCTAATACGTATCAGCTGTGACGTTA CTCGCAGAAGAAGCACCGGCTAACTCCGTGCCAGCAGCCGCGGTAAT ACGGAGGGTGCAAGCGTTAATCGGAATTACTGGGCGTAAAGCGCACG CAGGCGGTTGGATAAGTTAGATGTGAAAG

$>$ KLU11.16 R

CCCCGGGCTCAACCTGGGAATTGCATTTAAAACTGTCCAGCTAGAGT CTTGTAGAGGGGGGTAGAATTCCAGGTGTAGCGGTGAAATGCGTAGA GATCTGGAGGAATACCGGTGGCGAAGGCGGCCCCCTGGACAAAGACT GACGCTCAGGTGCGAAAGCGTGGGGAGCAAACAGGATTAGATACCCT GGTAGTCCACGCCGTAAACGATGTCGATTTGGAGGCTGTGTCCTTGA GACGTGGCTTCCGGAGCTAACGCGTTAAATCGACCGCCTGGGGAGTA CGGCCGCAAGGTTAAAACTCAAATGAATTGACGGGGGCCCGCACAAG CGGTGGAGCATGTGGTTTAATTCGATGCAACGCGAAGAACCTTACCT GGCCTTGACATGTCTGGAATCCTGTAGAGATACGGGAGTGCCTTCGG GAATCAGAACACAGGTGCTGCATGGCTGTCGTCAGCTCGTGTCGTGA GATGTTGGGTTAAGTCCCGCAACGAGCGCAACCCCTGTCCTTTGTTG CCAGCACGTAATGGTGGGAACTCAAGGGAGACTGCCGGTGATAAACC GGAGGAAGGTGGGGATGACGTCAAGTCATCATGGCCCTTACGGCCAG GGCTACACACGTGCTACAATGGCGCGTACAGAGGGCTGCAAGCTAGC GATAGTGAGCGAATCCCAAAAAGCGCGTCGTAGTCCGGATCGGAGTC TGCAACTCGACTCCGTGAAGTCGGAATCGCTAGTAATCGCAATCAAT CGG

$>$ JB4 F

CNNNNNNNNNNNNCNGCNNNNNNNNNNNNNNNNNNNNNNNNNNNNNNN NNNNNNNNNNNNCNNNNNNNAANACTGGNATAACTTCGGGAAACCGG AGCTAATNCCGGATAACATGTTGAACCGCATGGTTCAACNGTGAAAG ACGGTCTTGCTGTCACTTA

TAGATGGATCCGCGCCGCATTAGCTAGTTGGTAAGGTAACGGCTTAC CAAGGCAACGATGCGTANCCGACCTGAGAGGNTGATCGGCCACACTG GAACTGAGACNCGGTCCAGACTCCTACGGGAGGCAGCANNNGNNNNT CTTCCGCAATGNGCGAAAGCCTGACGGNNCAACGCCGCGTGAGTNAN GAANGTCTTCNNNTCGTAAAACTCTGTTATTAGGGAAGAACNNNTGT GTAAGTNNCTNTGCACGTCTTGACNGNNCCTAATCAGAAAGNCACGG NTAACTACNTGNCAGCNGCNNNNNNNNTNNNNANGNGGNAAGNGTTN NCCGGNATTANTGGNNGTAANGNGCGCNNNNNNNGTTTTTTNAN

$>\mathrm{JB} 4 \mathrm{R}$

CCGCN̄TATNCCTANGNCNGNCNTTTCANANNAGGNGGNNGNGNNANN CTGTTTTCCAGTTGCNGGGGNNAATCCGAACTGAGAACAACTTTATG GGATTTGCTTGACCTCGCGGTTTCGCTACCCTTTGTATTGTCCATTG TAGCACGTGTGTAGCCCAAATCATAAGGGGCATGATGATTTGACGTC ATCCCCACCTTCCTCCGGTTTGTCACCGGCAGTCAACTTAGAGTGCC CAACTTAATGATGGCAACTAAGCTTAAGGGTTGCGCTCGTTGCGGGA CTTAACCCAACATCTCACGACACGAGCTGACGACAACCATGCACCAC
CTGTCACTCTGTCCCCCGAAGGGGAAAACTCTATCTCTAGAGGGNTC AGAGGATGTCAAGATTTGGTAAGGTTCTTCGCGTTGCTTCGAATTAA ACCACATGCTCAACCGCTTGTGCGGGTCCCCGTCAATTCCCTTTGAG TTTTCAACCTTGGGGGTCGTACTCCCCAGGGNGNAGTGCTTAATGCG TTAGA

$>$ KPU2213 F

CGNCTNGTN̄ GNGGTTTCNCCGGNGNGGGGGGGNCGTGGGGGATAACTTAGGGAAAC TTACGCTAATACCGCATACGACCTACGGGTGAAAGCAGGGGACCTTC GGGCCTTGCGCGATTGAAT

GAGCCGATGTCGGATTAGCTAGTTGGCGGGGTAAAGGCCCACCAAGG CGACGATCCGTAGCTGGTCTGAGAGGATGATCAGCCACACTGGAACT GAGACACGGTCCAGACTCCTACGGGAGGCAGCAGTGGGGAATATTGT NTNNTGGGCGCAAGCCTGATCCAGCCATACCGCGTGGGTGAAGAAGG NCTTCGGNTTGTAAAGCCCTTTTGTTGNNAAAGAAATCCAGCCGGCT AAAACCTGGTTGGGATGACGGTACCNAAAGAATAAGCACCGGCTAAC TTCGTGCCACCAGCCGCGGTAATACGAAGGGTGCAAGCGTNACTCGG AATNACTGGGNGTAAANGCNTGCCGTAGGNGGTNAATTNANGCCC

$>$ KPU2213_R

CCGGANTTTTTCCTCAGNCAGGCTGTTTCANNNNNGNGGGGGGNNNG NNAACTNCNTGNTTNCNAGTTGGGGGNGGNNAATCCGGACTGAGATA GGGTTTCTGGGATTGGCTTACCGTCGCCGGCTTGCAGCCCTCTGTCC CTACCATTGTAGTACGTGTGTAGCCCTGGCCGTAAGGGCCATGATGA CTTGACGTCATCCCCACCTTCCTCCGGTTTGTCACCGGCGGTCTCCT TAGAGTTCCCACCATTACGTGCTGGCAACTAAGGACAAGGGTTGCGC TCGTTGCGGGACTTAACCCAACATCTCACGACACGAGCTGACGACAG CCATGCAGCACCTGTGTTCGAGTTCCCGAAGGCACCCATCCATCTCT GGAAAGTTCTCGACATGTCAAGGCCAGGTAAGGTTCTTCGCGTTGCA TCGAATTAAACCACATACTCCACCGCTTGTGCGGGCCCCCGTCAATT CCTTTGAGTTTCAGTCTTGCGACCGTACTCCCCAGGCGGCGAANTTA ACGCGTTAGCTTCGATAC

$>$ KPU218 F

CGGCATGĀGCACGGTCGGCGAGCATCACTTCAACTATGTGCTTCGTT CCTGCCTATTAGAGAGGCACACGTTCTCCGGGAGCGCTAATCCCGTA TACGTCCTACTGTAGAAACCCGGGGACCTTTGGTCCTTGGCCTAATC GATGAGCCTTTGTCGGAGTACCTGGTTGGTAGGGTAAAGGCCTACCG AGGCCACGATCTGTAGCGGGTCTGAGAGGATGATCCGCCACACTGGG TCTGACACACGGGCCATACTCCTACGGGAGGCAGCCGTGGGGAATAT TGGATAATGTTTTGTACCCTGATCCAGCCATGCCGCGTGTGTGAAGA CGGCCTATTGATTAAAAATCACTTTAAGCAAGAAGGAGGCTACCTAG ATTAATACTTGATGATAGTGGACGCTACTCGCATAACAAGAACTGGC CAACTCTGTGCCAGCAGCCGCGATAATACAGAGGGTGCGAGCGTTAA TCGGAATTACTGGGCGTAAAGCGTGCGTAGGCAAG

$>$ KPU218 R

CCGGAANT̄TNCCGGCGGCNTNCTGATCCGCGNTTACTAGCGATTCCG ACTTCATGTAGTCGAGTTGCAGACTACAATCCGGACTNCGATCGGCT TTTTGAGATTAGCNTCACATCGCNGTGTNGCAGCCCTTTGTACCGAC CATTGTAGCACGTGTGTAGCCCTGGCCGTAAAGGGCCATGATGACTT GACGTCNTCCCCGCCTTCCTCCNGTTTGTCACTGGCAGTATCCTTAA AGTNCCCACCCGAANNGCTGNNAAAATAAGGAAAAGGNTTGCGNTCG TNGCGGNANTTAACCCAACNTCTNACGACACGAGNTGANNACAGCCN TGNNGCACTGTGTATCATAGTNCCCGAAGGCACNAANTCATCTCTGG GAANGTCCTNTGTNTGCCAAAAGCCAGGTAAGGGTTCTTCNNGTTGC TTCGAANTNAACCACATGCTCCACCGCTTGTGCGGGCCCCCCGTCAA TTCNTTTTGAGTTTNAATCTTGCGACCGNACTCCCCAGGGGGANTAC TTATGGCGTAACTGCCCCACTAAAGCCTCAAAGNCCCNACGC

Analisis dilakukan dengan melakukan BLAST [13] untuk nukleotida menggunakan database Reference Genomic Sequence dan 16S Microbial dengan tidak mengikutsertakan sampel model dan lingkungan dalam database tersebut. Sekuen Gene Bank yang paling mirip; dicirikan dengan nilai Max Score dan Total Score sama, Query Coverage mendekati 100\%, E-value mendekati 0, dan Max Ident mendekati $100 \%$; pada setiap database kemudian diunduh dan dikonstruksi filogeninya dengan CLUSTALW2 [14]. Sekuen yang paling dekat 
dengan sampel merupakan sekuen yang kemiripanya paling tinggi.

\section{HASIL DAN PEMBAHASAN}

Berdasarkan dua database yang digunakan, diperoleh beberapa bakteri, namun semuanya tidak terdata sebagai bakteri penghasil kitosanase. Bakteri tersebut juga tidak menunjukkan kemiripan yang identik dengan sampel. Oleh karena itu, sampel berpeluang menjadi strain baru asli Indonesia yang belum terpublikasi.

Dalam membaca hasil tersebut, Query Coverage adalah parameter yang penting karena menilai dalam persen sekuen dalam database menutupi query, yang memastikan apakah sampel tertutup semuanya oleh sekuen. Persentase yang dapat diterima minimal 95\%, kecuali untuk sekuen yang bacaannya lebih rendah diberlakukan minimal $75 \%$. Apabila nilai E-Value semakin mendekati nol, hasilnya akan lebih terpercaya dan bila nilainya 1 , maka tidak boleh digunakan.

Beberapa hasil pembacaan pada Tabel 1 memberikan hasil genus yang sama, bahkan beberapa berada pada tingkat spesies yang sama. Namun beberapa ada yang berbeda. Perbedaan ini dapat dipecahkan dengan CLUSTALW2 untuk pensejajaran sekuen-sekuen yang dihasilkan, untuk kemudian dibuat filogeninya. Filogeni ini diperlukan karena merupakan salah satu cara yang penting untuk pembacaan sekuen mana yang paling dekat dengan sampel.

Tabel 1. Hasil BLAST Sekuen 16S RNA di NCBI

\begin{tabular}{|c|c|c|}
\hline Sampel & 16S Microbial Database & Reference Sequence Genomic Database \\
\hline T5a1 & Micromonospora chalcea strain 1464-217L & Micromonospora sp. L5 \\
\hline KPU 21.24 & $\begin{array}{l}\text { Aeromonas media strain RM Aeromonas hydrophila } \\
\text { strain CCM 7232; ATCC } 7966 \text { Aeromonas } \\
\text { hydrophila subsp. ranae strain : CIP }\end{array}$ & $\begin{array}{l}\text { Aeromonas salmonicida subsp. } \\
\text { salmonicida A449 } \\
\text { Aeromonas veronii B } 565 \\
\text { Aeromonas hydrophila subsp. hydrophila } \\
\text { ATCC } 7966\end{array}$ \\
\hline KLU 11.16 & $\begin{array}{l}\text { Aeromonas molluscorum strain } 848 \\
\text { Aeromonas media strain RM } \\
\text { Aeromonas hydrophila strain CCM } 7232 ; \text { ATCC }\end{array}$ & $\begin{array}{l}\text { Aeromonas salmonicida subsp. } \\
\text { salmonicida A449 } \\
\text { Aeromonas veronii B } 565 \\
\text { Aeromonas hydrophila subsp. hydrophila } \\
\text { ATCC } 7966\end{array}$ \\
\hline JB4 & $\begin{array}{l}\text { Staphylococcus capitis subsp. urealyticus strain } \\
\text { MAW } 8436\end{array}$ & $\begin{array}{l}\text { Staphylococcus epidermidis RP62A } \\
\text { Staphylococcus epidermidis ATCC } 12228\end{array}$ \\
\hline KPU 2213 & $\begin{array}{l}\text { Stenotrophomonas maltophilia strain IAM } 12423 \\
\text { Stenotrophomonas maltophilia strain ATCC } 19861 \\
\text { Pseudomonas geniculata strain ATCC } 19374\end{array}$ & $\begin{array}{l}\text { Burkholderia sp. JV3 } \\
\text { Stenotrophomonas maltophilia } \mathrm{R} 551-3 \\
\text { Stenotrophomonas maltophilia } \mathrm{K} 279 \mathrm{a}\end{array}$ \\
\hline KPU 218 & Acinetobacter radioresistens DSM 6976 & $\begin{array}{l}\text { Acinetobacter baumannii } \mathrm{AB} 307-0294 \\
\text { Acinetobacter baumannii AB0057 }\end{array}$ \\
\hline
\end{tabular}

Tabel 2. Hasil Identifikasi Mikroba dengan Tree View

\begin{tabular}{ll}
\hline Sampel & Mikroba Teridentifikasi \\
\hline T5a1 & Micromonospora sp. L5 \\
KPU 21.24 \& KLU 11.16 & $\begin{array}{l}\text { Aeromonas veronii B565 } \\
\text { Staphylococcus } \\
\text { JB4 }\end{array}$ \\
epidermidis ATCC 12228 \\
KPU 2213 & Burkholderia sp. JV3 \\
KPU 218 & $\begin{array}{l}\text { Acinetobacter baumannii } \\
\text { AB307-0294 }\end{array}$ \\
\hline
\end{tabular}


Micromonospora sp. L5-Bakteri ini diisolasi dari akar Casuarina equisetifolia, tanaman actinorhizal yang dinodulasi oleh Frankia yang diketahui berperan untuk mengubah nitrogen atmosfer menjadi ammonia [15]. Spesies Micromonospora sp. dapat hidup secara saprofit (hidup di jaringan mati) dan berpotensi simbiosis. Habitat dapat ditemukan di tanah, sedimen, lingkungan air tawar, air laut, tambak, dan bahkan dalam rumen ternak [16]. Taxonomy: Bacteria; Actinobacteria; Actinobacteria (class); Actinobacteridae; Actinomycetales; Micromonosporineae; Micromonosporaceae; Micromonospora.

Aeromonas veronii B565-Aeromonas spp. adalah bakteri gram-negatif yang berbentuk batang yang ditemukan di seluruh lingkungan perairan di seluruh dunia, bahkan termasuk dalam air kemasan, air terklorinasi, dan air tercemar. A. veronii strain B565 diisolasi dari kolam budidaya di Tianjin, Cina [16]. Taxonomy: Bacteria; Proteobacteria; Gammaproteobacteria; Aeromonadales; Aeromonadaceae; Aeromonas; Aeromonas veronii; Aeromonas veronii B565.

Staphylococcus epidermidis ATCC 12228Staphylococcus epidermidis merupakan bakteri kokus Gram-positif nonmotil yang tumbuh dalam kondisi aerobik dan anaerobik dan membentuk koloni seperti anggur. Jumlahnya yang besar dan distribusi yang luas menjadikan bakteri ini salah satu mikroba yang paling sering terisolasi di laboratorium klinis. S. epidermidis (strain ATCC 12228) tidak dapat membentuk biofilm [16]. Taxonomy: Bacteria; Firmicutes; Bacilli; Bacillales; Staphylococcaceae; Staphylococcus; Staphylococcus epidermidis.

Burkholderia sp. JV3-Burkholderia dikenal sebagai mikroba yang paling serbaguna yang mensintesis lebih dari 200 senyawa organik, memperbaiki $\mathrm{N}_{2}$, dan membawa beberapa resistensi antibiotik. Burkholderia sp. diisolasi pada tahun 1958 dari sebuah tanah hutan di Trinidad [16]. Taxonomy: Bacteria; $\quad$ Proteobacteria; Betaproteobacteria; Burkholderiales; Burkholderiaceae; Burkholderia.

\section{Acinetobacter baumannii AB307-0294- Acinetobacter baumannii umum ditemukan di lingkungan rumah sakit dan pasien yang sedang di rawat. Bakteri ini bersifat patogen pada manusia dan biasanya menginfeksi pada daerah luka, sistem pernafasan, dan urin [16]. Taxonomy: Bacteria;}

Proteobacteria; $\quad$ Gammaproteobacteria; Pseudomonadales; Moraxellaceae; Acinetobacter; Acinetobacter calcoaceticus/baumannii complex.

Kelima mikroba tersebut dalam Gene Bank [17] tidak memiliki gen penyandi kitosanase, tetapi mempunyai gen kitinase. Ketidakhadiran gen kitosanase pada setiap genome mikroba yang teridentifikasi dapat menandakan bahwa lima mikroba tersebut adalah bakteri baru yang belum tersekuen gen kitosanasenya

Tabel 3. Gen Kitinase pada Mikroba Teridentifikasi

\begin{tabular}{|c|c|}
\hline Bakteri & Gen Terkait \\
\hline $\begin{array}{l}\text { Micromonospora } \\
\text { sp. L5 }\end{array}$ & $\begin{array}{l}\text { Kitinase (ML5_2712); gi } \\
\text { 315500818: 2840251-2842803 }\end{array}$ \\
\hline $\begin{array}{l}\text { Aeromonas veronii } \\
\text { B565 }\end{array}$ & $\begin{array}{l}\text { Kitinase (putative); } \\
\text { gb CP002607.1:2263709- } \\
2265172 \\
\text { Kitinase 92; gb CP002607.1 } \\
: 929673-932267 \\
\text { Kitinase A; gb CP002607.1 } \\
: 934136-936748\end{array}$ \\
\hline $\begin{array}{l}\text { Staphylococcus } \\
\text { epidermidis ATCC } \\
12228 \\
\end{array}$ & $\begin{array}{l}\text { Kitinase B; gb AE015929.1: } \\
\text { 749934-750251 }\end{array}$ \\
\hline $\begin{array}{l}\text { Burkholderia sp. } \\
\text { JV3 }\end{array}$ & $\begin{array}{l}\text { Kitinase A; gb CP002986.1: } \\
\text { 620845-622944 } \\
\text { Kitinase; gb CP002986.1: } \\
\text { 3107298-3108488 }\end{array}$ \\
\hline $\begin{array}{l}\text { Acinetobacter } \\
\text { baumannii AB307- } \\
0294\end{array}$ & $\begin{array}{l}\text { Polysaccharide deacetylase } \\
\text { family protein (Predicted } \\
\text { xylanase/chitin deacetylase); gb } \\
\text { CP001172.1: 146545-147510 } \\
\text { Polysaccharide deacetylase } \\
\text { family protein (Predicted } \\
\text { xylanase/chitin deacetylase); gb } \\
\text { CP001172.1: 586979-587734 }\end{array}$ \\
\hline
\end{tabular}

Micromonospora sp. L5 dan Burkholderia sp. JV3 mempunyai jenis kitinase yang sama. Jenis kitinase yang putative dimiliki oleh Aeromonas veronii B565 yang juga mempunyai kitinase A dan 92. Kitinase A ini juga dimiliki oleh Burkholderia sp. Berbeda lain dengan Staphylococcus epidermidis ATCC 12228 yang mempunyai kitinase B. Pada Acinetobacter baumannii AB307-0294, tidak ditemukan baik gen kitosanase maupun kitinase. Namun demikian, terdapat gen penyandi protein yang diprediksi sebagai kitin deasitelase.

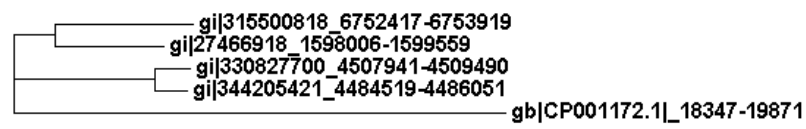

Gambar 1. Tree View Mikroba yang Teridentifikasi 
Dengan menggunakan database lain untuk protein, UNIPROT [18] dari lima mikroba di atas hanya spesies Burkholderia sp. JV3 yang genusnya, Burkholderia, terdaftar sebagai penghasil protein kitosanase. Di antaranya adalah: Burkholderia gladioli (Pseudomonas marginata) (Phytomonas marginata) dan Burkholderia gladioli (strain BSR3) yang mempunyai kitosanase A, serta Burkholderia rhizoxinica (strain DSM 19002/CIP 109453/HKI 454) dengan kitosanase (EC 3.2.1.132).

Tree view dari lima kandidat mikroba yang teridentifikasi, dengan menggunakan query $16 \mathrm{~S}$ rRNA, menggambarkan bahwa sampel KPU 218 yang teridentifikasi sebagai Acinetobacter baumannii AB307-0294, memiliki kekerabatan yang paling jauh dengan empat mikroba lain. Sampel T5a1 yang teridentifikasi sebagai Micromonospora sp. L5 lebih dekat dengan sampel JB4 yang teridentifikasi sebagai Staphylococcus epidermidis ATCC 12228. KLU 11.16 dan KPU 21.24 yang teridentifikasi sebagai Aeromonas veronii B565 lebih dekat dengan sampel KPU 2213 yang teridentifikasi sebagai Burkholderia sp. JV3.

\section{KESIMPULAN}

Berdasarkan hasil identifikasi filogeni (kekerabatan) 6 sampel 16S rRNA diketahui bahwa keenam sampel tidak identik dengan database di Gene Bank, namun mempunyai kemiripan dengan 5 bakteri, yaitu Micromonospora sp. L5, Aeromonas veronii B565, Staphylococcus epidermidis ATCC 12228, Burkholderia sp. JV3, dan Acinetobacter baumannii AB307-0294. Kelima mikroba tersebut dalam Gene Bank memiliki gen penyandi kitinase, yang erat hubungannya dengan kitosanase. Ketidakhadiran gen kitosanase pada setiap genome mikroba yang teridentifikasi dapat menandakan bahwa lima mikroba tersebut adalah bakteri baru yang belum tersekuen gen kitosanasenya. Hal ini dapat memberikan peluang untuk eksplorasi dan publikasi sekuen ke Gene Bank dan menambah kepustakaan gen dunia.

\section{DAFTAR PUSTAKA}

[1] National Center for Biotechnology Information (2011). Terdapat online di http://www.ncbi. nlm.nih.gov/ (1 Februari 2011).
[2] Pharmaexenews.com (2009). Bioinformatics: Analysis Of Market And Developments. Terdapat di http://pharmaexecnews.com/tag/importance-ofbioinformatics/ (13 Februari 2011).

[3] Teknat (Teknik Och Naturvetenskap) (2008). Bioinformatics. Uppsala Universitet. Terdapat di http://www.teknat.uu.se/forskning/program.php?vet enskapsid=1\&hforskomr=6\&id=81\&lang=en) Februari 2011).

[4] Jhala, M.K., et al. (2011). Role of Bioinformatics in Biotechnology. Information Technology Centre, GAU, Anand. Terdapat di http://openmed.nic.in/ 1383/01/Role_of_Bioinformatics_in_Biotechnology .pdf (5 Februari 2011).

[5] Luscombe, M.L., et al. (2001). What is bioinformatics? An introduction and overview. Yearbook of Medical Informatics, pp. 83-100. Terdapat di http://papers.gersteinlab.org/e-print/ whatis-imia/text.pdf (8 Februari 2011).

[6] Enzyme Commission. 2011. Chitosanase EC 3.2.1.132. Terdapat online di http://www.chem. qmul.ac.uk/iubmb/enzyme (8 Februari 2011).

[7] Li, H. \& Greene, L.H. (2010). Sequence and Structural Analysis of the Chitinase Insertion Domain Reveals Two Conserved Motifs Involved in Chitin-Binding. PLoS One. 5 (1): e8654.

[8] Yang, J., et al. (2010). Crystal structure and mutagenesis analysis of chitinase CrChi1 from the nematophagous fungus Clonostachys rosea in complex with the inhibitor caffeine. Microbiology. 156: $3566-3574$.

[9] Gerstein, M. (2011). Bioinformatics: Introduction. Yale University. Terdapat di http://bioinfo. mbb.yale.edu/mbb452a/intro/ (6 Februari 2011).

[10] Nilges, M. \& Linge, J.P., (2011). Bioinformatics: a definition. Unité de Bio-Informatique Structurale, Institut Pasteur, 25-28 rue du Docteur Roux, F75015 Paris, France. Terdapat di http://www.pasteur.fr/recherche/unites/Binfs/definiti on/bioinformatics_definition.html (10 Feruari 2011).

[11] Beier, S., et al. (2011). Global Phylogeography of Chitinase Genes in Aquatic Metagenomes. Applied and Environmental Microbiology. 77 (3): 11011106.

[12] Sitrit, Y., et al. (1995). Cloning and Primary Structure of the chiA Gene from Aeromonas caviae. Journal of Bacteriology. 177 (14): 4187-4189.

[13] BLAST (2011). Terdapat online di http://blast.ncbi.nlm.nih.gov/Blast.cgi (18 Februari 2011).

[14] CLUSTALW2 (2011). Terdapat online di http://www.ebi.ac.uk/Tools/msa/clustalw2/(20 Februari 2011).

[15] US Department of Energy [DOE] (2011) Micromonospora sp. L5. Proyek DOE Join Genome Institute. Kerjasama US Department of Energy, Office of Science, dan University of California. Terdapat di http://genome.jgi-psf.org/mic_l/ mic_l. home.html (1 Oktober 2011). 
[16] HAMAP. Swiss Institute of Bioinformatics (2011). Terdapat di http://192.33.215.45/sprot/ hamap/ MICSL.html (1 Oktober 2011).

[17] Gene Bank (2011). Terdapat online di http://www.ncbi.nml.nih.gov/genebank/(25 Februari 2011).
[18] UNIPROT (2011). Terdapat online di http://www. uniprot.org (25 Februari 2011). 